\title{
ROOF PITCH ANGLE EXAMINATION FOR WIND TURBINE INSTALLATION
}

\author{
Csaba HETYEI, ${ }^{1}$ Ferenc SZLIVKA ${ }^{2}$ \\ ${ }^{1}$ Óbuda University, Doctoral School on Safety and Security Sciences, Budapest, Hungary, \\ hetyei.csaba@phd.uni-obuda.hu \\ ${ }^{2}$ Óbuda University, Donát Bánki Faculty of Mechanical and Safety Engineering, Budapest, Magyarország, \\ szlivka.ferenc@bgk.uni-obuda.hu
}

\begin{abstract}
Due to the current increase in energy demand, renewable energy sources and their utilization have become a priority. Thanks to the Smart Grid, which is currently under development, and with the help of the evolving technologies, we are trying to extract more and more energy from sources that we couldn't exploit before or which weren't economically viable. In this article, we examine the airflow field for a theoretical warehouse building, dependent on roof inclination angle. The purpose of the analysis was to select the optimal angle under which a roof mounted horizontal axis wind turbine (HAWT) could perform efficiently.
\end{abstract}

Keywords: $C F D, B A W T$, HAWT, simulation.

\section{Introduction}

Due to the current growth in energy demand, renewable sources that can be integrated in a decentralized smart grid - such as biomass, geothermal, water and wind power - are gaining more importance.

In the market of renewable energy sources we are witnessing a year by year increase. According to a UNEP study [1] in 2017, estimated new investment was 208.2 billion USD, of which 161 billion USD was for solar and 107 billion USD for wind energy.

In our article, we discuss the utilization of wind power, in particular, that of a small size wind turbine which is easily installable in urban areas. We chose this topic because in the currently available literature it either can't be reproduced, or if it can, it poses great difficulties, so we can't use them as input for future research. For example Y. Ozmen et al. [2] examined a gable roof that had a certain slope. I. Abohela et a [3] and L. Ledo et al. [4] investigated several roof types in a small town environment with different buildings and wind attack angles.

\section{Using wind power in urbanized en- vironments}

In an urban environment, only small scale wind turbines can be installed (due to their size). According to the IEC64100-2 standard, the small wind turbines' rotor sweeping area has to be smaller than $200 \mathrm{~m}^{2}$ and the generated voltage must be below $1000 \mathrm{~V}$ (AC) or $1500 \mathrm{~V}$ (DC) [5].

Worldwide, the share of these turbines is low, with $948.9 \mathrm{MW}$ of installed power in 2015 representing $0.22 \%$ of the total global installed wind turbine performance.

According to forecasts, by 2020, $1.9 \mathrm{GW}$ of small scale wind power will be installed worldwide [5]. In terms of percentage distribution, it appears negligible but, small scale wind turbines could play an important role in near future energy supply because such turbines can be installed in densely inhabited zones' smart grid system and also in areas that are far from the power network. According to Casini [6] ], there are three different types of BAWTs (Building Augmented Wind Turbines):

- BAWT close to the buildings;

-BAWT between buildings; 
- BAWT inserted in air conducts through buildings.

The first type involves a wind turbine on the rooftop or along the sides (this is the type that we will examine in our article). For the second, the World Trade Center in Bahrain; for the third the Pearl River Tower in Guangzhou are good examples (shown in Picture 1. and 2.).

In each of the three cases, the space where air can flow decreases near the building, so the wind must flow around the building or pass through the wind tunnel. Since the available space is less than in free wind flow, according to the continuity equation, its speed must increase. In the accelerated flow there is more kinetic energy than in free flow, so the wind turbines can produce more energy compared to free flow.

\section{About the finite volume method}

We have selected for computational fluid dynamics (CFD) simulation the SOLIDWORKS Flow Simulation, which is a finite volume method (FVM) software integrated into the SOLIDWORKS CAD system.

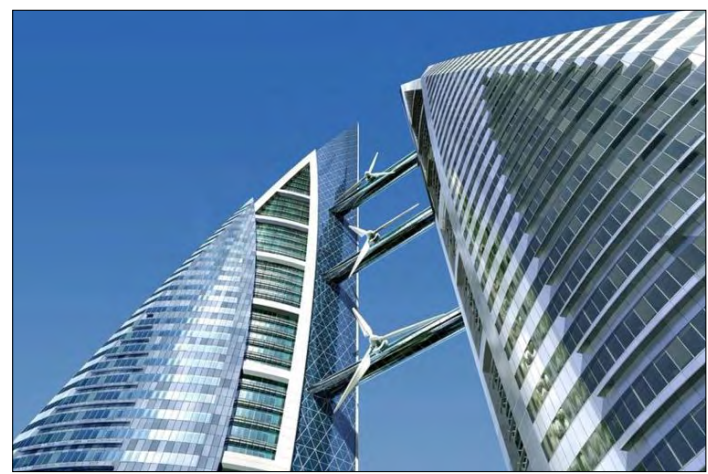

Picture 1. World Trade Center in Bahrain [7]

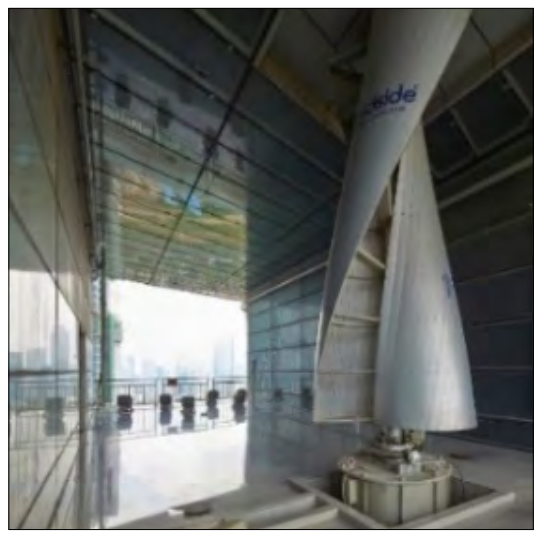

Picture 2. Pearl River Tower in Guangzhou [6]
The FVM based simulation software splits the space into finite volume cells and for these discrete parts calculates the pressure, velocity and temperature fields using the continuity equations and typically the following transport equation:

$\frac{\partial}{\partial t} \int_{V} U d V+\oint_{A} \underline{F} d \underline{A}-\int_{V} S_{V} d V+\oint_{A} \underline{S}_{A} d \underline{A}=0$

In the equation $\partial / \partial t$, is the time dependent term (in steady state it is 0 ), $U$ is the volumetric density of a residual quantity (e.g. mass, momentum, energy), $\mathrm{F}$ is the characteristic flux, $\mathrm{S}_{\mathrm{V}}$ and $\mathrm{S}_{\mathrm{A}}$ are the volumetric and the surface source for the given $\mathrm{F}$ flux.

The simulation software performs the computations for the discretized field iteratively, until the simulation reaches the criterion that stops it. Typically, this stop criterion is a value that approaches 0 with a negligible error (in the above transport equation's right side).

\section{Examined case}

For our analysis we chose the roof structure of a warehouse. The examined geometry is shown in Figure 1.

During the simulation, we assumed a two-dimensional flow. With this simplification we analyzed a cross-section, where the fluid flow at every point of its length is the same as in every other parallel plane. As such the length is negligible. The width was 20 meters and the highs was between 5.375 and 10.275 meters depending on the roof angle. The examined angles were between $5^{\circ}-30^{\circ}$ in $5^{\circ}$ increments.

With this geometry we searched for the case in which the wind speed is as high as possible above the roof ridge, because that provides the most kinetic energy to the roof mounted wind wheels. In order to measure the wind speed we created a

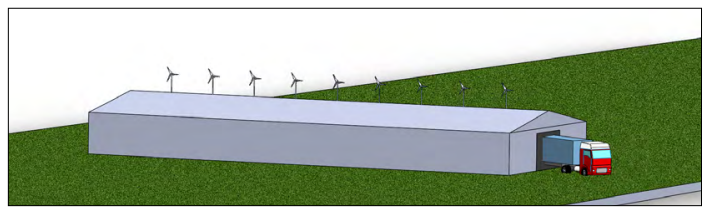

Figure 1. Examined building and its environment

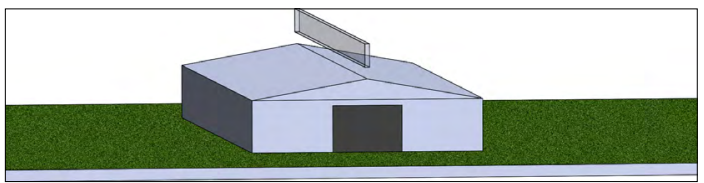

Figure 2. Control volume above the roof ridge 
control volume 1 meter above the roof ridge with a dimension of $0.4 \mathrm{~m} \times 2 \mathrm{~m}$ (the length is negligible because of the $2 \mathrm{D}$ flow).

\subsection{Boundary conditions}

The analyzed airflow space was a $270 \times 40$ meter rectangle, the location of the building within that domain is shown in Figure 3.

The speed of the wind entering the airflow space is $10 \mathrm{~m} / \mathrm{s}$ at a height of $10 \mathrm{~m}$, at the other heights it corresponds with the suggested velocity formula given by the WMO (World Meteorological Organization) [7]. The velocity profile can be calculated using the following equation, and its value in our case is shown in Figure 4.

$$
\mathrm{v}_{\mathrm{h}}=\mathrm{v}_{10} \cdot(0,233+0,656 \cdot \lg (\mathrm{h}+4,75))
$$

In the equation, $v_{h}$ is the estimated speed of the wind at the altitude at which we examined it, $\mathrm{v}_{10}$, the wind speed at 10 meters, and $h$, the altitude.

We used k- $\varepsilon$ to describe turbulence in the flow field.

In the airflow space all surfaces were considered to be ideal, so there was no surface roughness. In addition, the flow in the space was not influenced by any built or living environmental elements.

\subsection{Mesh}

As the name shows, the finite volume method splits the airflow space into finite volume elements.

Figure 3. The analyzed domain

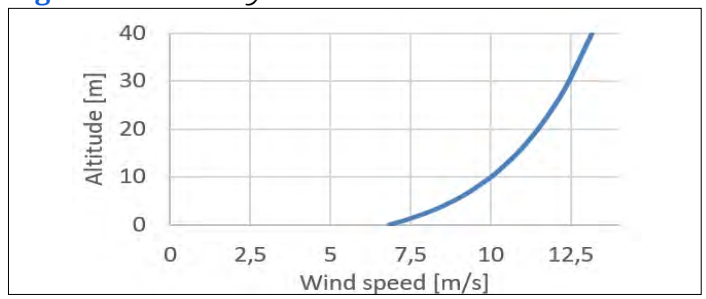

Figure 4. For winds of $10 \mathrm{~m} / \mathrm{s}$ the wind speed profile is between 0 and 40 meters
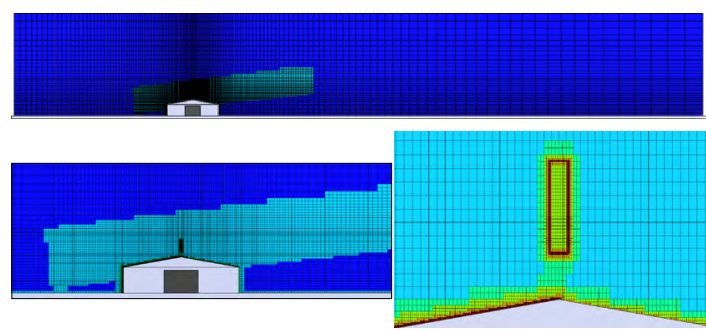

Figure 5. The CFD mesh for the $10^{\circ}$ configuration"
The software that we chose creates a block-structured mesh with rectangular elements to discretize the flow field.

In the examined cases the number of the elements varied between 231412 and 239276 pieces depending on the roof inclination angle.

Figure 5. shows a mesh grid for the $10^{\circ}$ angle configuration. The blue elements represent the cells without refinements and going towards red shows the number of refinements (red means five refinements).

\subsubsection{Mesh independence studies}

To ensure the reliability of our results we ran some mesh independency simulations with both coarse and finer mesh with the $10^{\circ}$ configuration. The results are shown in Figure 6.

\subsection{About the simulations}

We ran the simulations in steady state until 200 iterations, then continued as a time-dependent simulation. The transient simulation provided two stop conditions, it had to stop after 40 seconds or 15000 iterations. In all of these conditions, the 15000 iterations were completed first, depending on the angle, between 31 and 35 seconds. The time step was set to automatic, varying between 0.000987 and 0.003097 seconds. Examining the time steps for all cases, the average time stepping was 0.0020975 seconds.

The control volume's average speed was an observed value during the simulation. At the end of the simulation we found that it fluctuated around a value, as it was expected due to turbulence. For comparison, we did not use the entire time series, just the average of the last one second of observed values.

\subsection{Results}

For the simulation results we found different average velocity values and different airflow fields (as expected). For the $15^{\circ}$ roof inclination angle the velocity field is shown in Figures 7. and 8.

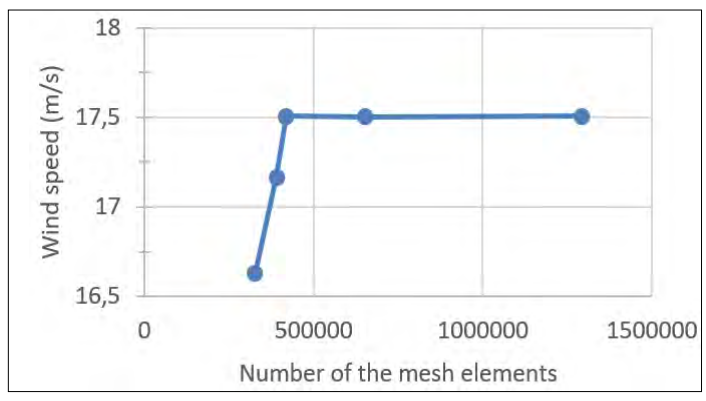

Figure 6. Average wind velocity in the control volume 


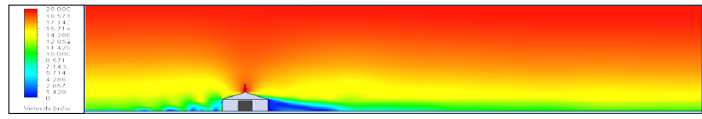

Figure 7. The velocity field for the $15^{\circ}$ inclination angle for the entire airflow space

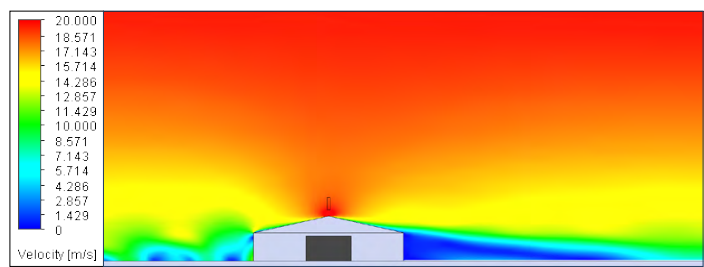

Figure 8. The velocity field for the $15^{\circ}$ inclination angle in the building's environment

\subsection{Evaluation of results}

The results were analyzed with different curve fitting methods, these are shown in Figure 9.

We have chosen the quadratic spline fitting, which is shown in Figure 10. (For a more accurate start and end points fitting we have run the simulation for $0^{\circ}$ and $35^{\circ}$ too.) As shown in the Figure 10., the maximum average wind velocity is $18.9486 \mathrm{~m} / \mathrm{s}$ at the $14.2208^{\circ}$.

\section{Conclusions}

In the presented case, we analyzed a warehouse with a gable roof assuming a two-dimensional airflow.

The focus of our study was to change the slope of the roof between $5^{\circ}$ to $30^{\circ}$ in $5^{\circ}$ increments and see how that changes the flow field. To find the energetically most efficient angle we used several curve fitting methods, of which we chose the quadratic spline function. With this spline we found that the average wind velocity in the control volume occurs near the $15^{\circ}$ value, more precisely at $14.22^{\circ}$.

Using these results, we will be able to compare the 2.5D and 3D simulation results with the current 2D (plane flow) cases. In the 3D case we will also be able to apply wind turbine geometry, so we can simulate its performance.

The final goal of our research is to choose a slope and possibly a guide baffle for gable roofs with which a wind turbine can work optimally and thus become an important part of the smart grid.

\section{Acknowledgement}

Supported by the ÚNKP-18-3-I-OE-87 New National Excellence Program of the Ministry of Human Capacities.

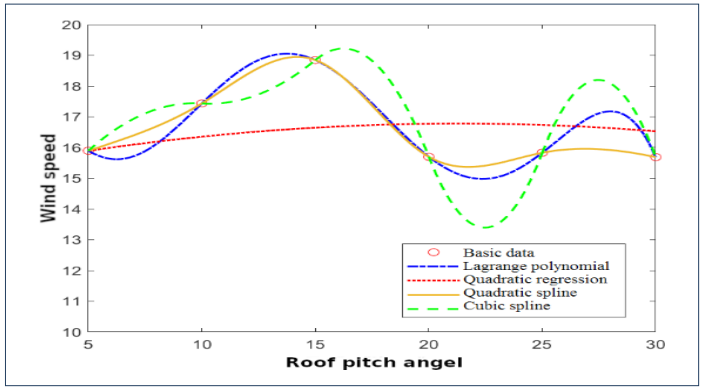

Figure 9. The average wind speed in the control volume depending on the roof inclination angle (with different curve fittings)

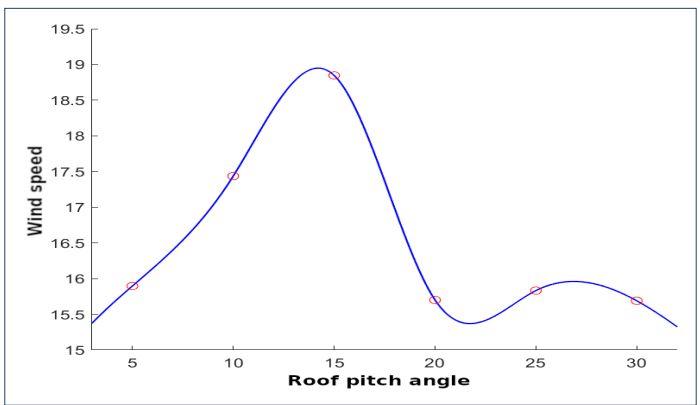

Figure 10. The average wind speed in the control volume versus the inclination angle

\section{References}

[1] Frankfurt School - UNEP Collaborating Centre for Climate \& Sustainable Energy Finance: Global trends in renewable energy investment 2018 p. 15. https://europa.eu/capacity4dev/file/71900/download?token=57xpTJ4W

[2] Ozmen Y., Baydar E., van Beeck J. P. A. J.: Wind flow over the low-rise building models with gabled roofs having different pitch angles. Building and Environment, 95. (2016) 63-74.

https://doi.org/10.1016/j.buildenv.2015.09.014

[3] Islam Abohela, Neveen Hamza, Dudek S.: Effect of roof shape, wind direction, building height and urban configuration on the energy yield and positioning of roof mounted wind turbines. Renewable Energy, 50. (2013) 1106-1118.

https://doi.org/10.1016/j.renene.2012.08.068

[4] Ledo L., Kosasih P. B., Cooper P.: Roof mounting site analysis for micro-wind turbines, Renewable Energy, 36. (2011) 1379-1391.

https://doi.org/10.1016/j.renene.2010.10.030

[5] World Wind Energy Association: 2017 Small Wind World Report. WWEA Head Office, Bonn 2017.

https://www.wwindea.org/wp-content/uploads/ filebase/small_wind_SWWR2017-SUMMARY.pdf

[6] Casini M.: Small Vertical Axis Wind Turbines for Energy Efficiency of Buildings. Journal of Clean Energy Technologies, 4/1. (2016) 56-65.

[7] Tóth Gábor: Energia célú szélmérés. Gödöllő, 2005. 